\title{
Seroprevalence and Molecular Detection of Influenza A Virus (H1N1) in Sulaimani Governorate-Iraq
}

\author{
Kaziwa Ahmad Kaka Alla1, Salih Ahmed Hama ${ }^{1,2}$ \\ ${ }^{1}$ Department of Biology, College of Science, University of Sulaimani, Kurdistan Region, Sulaymaniyah, Iraq, ${ }^{2}$ Department of Medical \\ Laboratory Science, College of Health Sciences, University of Human Development, Kurdistan Region, Sulaymaniyah, Iraq
}

\section{A B S T R A C T}

Influenza $A(\mathrm{H} 1 \mathrm{~N} 1)$ virus is now rapidly scattering across the world. Early detection is one of the most effective measures to stop the further spread of the virus. The current study was aimed to detect influenza A (H1N1) serologically and by polymerase chain reaction (PCR) techniques. From September 2020 to June 2021, three hundred nasopharyngeal swabs and blood samples were collected from Hiwa and Shahid Tahir Hospitals in Sulaimani city. Obtained results revealed that $23.3 \%$ of the tested patients were seropositive anti-IgG for Influenza A, while $13.3 \%$ showed anti-IgM seropositive results although $10 \%$ of the tested cases were with both anti-IgG and anti-lgM seropositive results. Gender, residency, and flu symptoms showed no significant relations with seropositive results $(p<0.05)$ whereas valuable relations were found between seropositive observations and smoking, the previous history of chronic diseases as well as employment status $(\mathrm{p}<0.05)$. It was concluded that hematologic investigations $(\mathrm{CBC})$ were not dependable if $\mathrm{H} 1 \mathrm{~N} 1 \mathrm{diagnosis}$ and detection. Only $1 \%$ of the tested samples showed positive results for influenza A (H1N1) RNA using reverse transcription-PCR.

Index Terms: Influenza A, H1N1, Anti-IgG, Anti-IgM, Reverse transcription-polymerase chain reaction, ssRNA

\section{INTRODUCTION}

Influenza viruses which are enveloped ssRNA viruses can cause annual epidemics and pandemics with serious consequences for public health and the global economy, assessed with 1 billion cases, including 3-5 million severe cases, and 290 000-650 000 influenza-related respiratory deaths worldwide [1]. Influenza A virus (IAV) is due to the family Orthomyxoviridae which possess a segmented, single-stranded, negative-sense RNA genome. This family consists of five genera: Influenzavirus A, B, and C, Togavirus [2]. The virus

\section{Access this article online}

DOI: 10.21928/uhdjst.v6n1y2022.pp1-6

E-ISSN: 2521-4217

P-ISSN: 2521-4209

Copyright (C) 2022 Alla and Hama This is an open access article distributed under the Creative Commons Attribution Non-Commercial No Derivatives License 4.0 (CC BY-NC-ND 4.0) is with a pleomorphic morphology, characterized by spherical, elongated, or filamentous particles [3]. In 2009 a pandemic influenza infection was caused by a subtype known as swine flu (H1N1) virus with genes that originate from human and avian influenza virus [4]. Humans can be infected with H1N1, H1N2, or H3N2 through direct contact with infected animals or contaminated surroundings. The pandemic strain contains genes from four different flu viruses including two swine strains, one human strain, and one avian [5]. Enveloped viruses have a matrix that interacted with the viral glycoproteins and nucleocapsid that can play an essential role in the gathering of the viral proteins and budding of the progeny virions [6]. Novel re-assorted influenza H1N1 virus produced by reassortment between the viral genome segments and it was behind the pandemic H1N1 in 2009 [7]. During the past 100 years, five pandemic influenza outbreaks have occurred Spanish flu (H1N1) in 1918, Asian flu (H2N2) in 1957, Hong Kong flu (H3N2) in 1968, Russian flu (H1N1) 1977, and swine flu

Corresponding author's e-mail: kaziwaahmad91@gmail.com

Received: 14-08-2021

Accepted: 28-12-2021

Published: 02-01-2022 
(H1N1) in 2009. In particular, the 1918 influenza pandemic affected almost $30 \%$ of the global population and is believed to have killed over 50 million people [8]. Multiple one-step real-time reverse transcription-polymerase chain reaction (RTPCR) assays can simultaneously detect and discriminate Flu A subtypes with dependable sensitivity and specificity, which is required for the early clinical diagnosis and viral surveillance of patients with Flu A infection [9].

Serological techniques commonly can be depended on for detection of Influenza A infections through anti-influenza Immunoglobulin $\mathrm{G}$ ( $\mathrm{IgG}_{-}$and $\operatorname{IgM}$ detection by ELISA technique, especially $\operatorname{IgG}$ and $\operatorname{IgM}$ against hemagglutinin [10]. The aims of the current study are; serologic detection of Influenza anti-IgG and anti-IgM and molecular detection of Influenza RNA using RT-PCR.

\section{MATERIALS AND METHODS}

\subsection{Study Population}

The study's population included people visiting Hiwa and Shahid Tahir Hospitals in Sulaimani city from September 2020 to June 2021, difficulties were found during sample collection due to the negative view of the patients. All tested patients were suffered from flue signs and symptoms, including fever, chills, cough, muscle or body aches, runny or stuffy nose, sneeze, headaches, fatigue, sore throat, and sweating. The sample size was 300 patients included 163 males and 137 females.

\subsection{Sample Collection}

From each tested patient nasopharyngeal swabs were collected as well as $5 \mathrm{~mL}$ fresh venous blood was taken aseptically and divided into two parts; one for serum preparation and the rest for hematologic investigations. The collected samples were stored according to their uses as following: the blood samples were stored in $4^{\circ} \mathrm{C}$ till hematological investigations were done. The serum samples were divided into two parts; one for serology and stored in $-20^{\circ} \mathrm{C}$, while the other part of the separated serum was stored in $-80^{\circ} \mathrm{C}$ (for molecular tests).

\subsection{Anti-Influenza Virus Antibody Detection by ELISA}

Indirect-ELISA method was depended to detect anti-Influenza virus $\mathrm{A}$ antibody $\operatorname{IgG}$ and $\operatorname{IgM}$ using a special ELISA kit (CUSABIO/Whan-China, Elab-Science/Korea, NovaLisa ${ }^{\circledR} /$ Germany). The microtiter plate wells were precoated with recombinant influenza antigens. All preserved sera samples were transferred to room temperature for about $30 \mathrm{~min} .100 \mu \mathrm{L}$ of each diluted sample, standard, and blank were added to the desired wells for IgM (for IgG $200 \mu \mathrm{L}$ of diluted sample was added). The plate was incubated for $30 \mathrm{~min}$ but (an hour for IgM according to supplied company instructions) at $37^{\circ} \mathrm{C}$ in shading light. The process of washing and aspirating of each well with $350 \mu \mathrm{l}$ washing buffer was done five times for IgM using ELISA washer (for IgG $300 \mu \mathrm{l}$ of washing buffer was used four times as directed by the supplied company). About $100 \mu \mathrm{L}$ of HRP conjugate was added to each well except the blank and incubated for $30 \mathrm{~min}$ at $37^{\circ} \mathrm{C}$ in shading light. The process of washing was repeated and aspirated five times for IgM and four times for IgG. To each well, $50 \mu \mathrm{L}$ of the substrate reagent $\mathrm{A}$ and $50 \mu \mathrm{L}$ substrate reagent $\mathrm{B}$ was added and mixed, then incubated for $15 \mathrm{~min}$ at $37^{\circ} \mathrm{C}$ in shading light for both IgG and IgM. For each well, $50 \mu \mathrm{L}$ of stop solution was added and the Optical Density was measured at $450 \mathrm{~nm}$ and $620 \mathrm{~nm}$ for IgG and IgM.

\subsection{Viral RNA Extraction and Amplification}

The RNA extraction was performed according to the manufacturer's protocol included in AddPrep Viral Nucleic Acid Extraction Kit (Add Bio-Tech, Korea). AddPrep Viral Nucleic Acid Extraction Kit (Add Bio-Tech/Korea) buffer system provides the effective binding condition of RNA to the microfiber-silica-based membrane through the mix with lysis and binding buffers, and then the impurities on the membrane are washed away by two different washing buffers. Starting with a $200 \mu \mathrm{L}$ of swab sample to 1.2 tubes and followed spin column purification with final elute of $150 \mu \mathrm{L}$ RNA. Extracted viral nucleic acid was stored at $-80^{\circ} \mathrm{C}$ until the day of examination.

\subsection{PCR Reaction}

A total volume of Master Mix AddScript RT-PCR Nuclease-free (D.W), Forwarding primer, Reverse primer, and nasopharyngeal swab fluid/standard/Negative/Positive Control was prepared as directed by the supplied company. The process of PCR programming for detecting IVA nucleic acid was performed starting with the reverse transcription step, denaturation, renaturation, annealing, elongation, and the data were collected.

\begin{tabular}{lccc}
\hline Step & Temperature $\left({ }^{\circ} \mathrm{C}\right)$ & Duration & Cycle \\
\hline cDNA synthesis & 50 & $30 \mathrm{~min}$ & 1 \\
initial denaturation & 95 & $10 \mathrm{~min}$ & \\
Denaturation, & 95 & $15-30 \mathrm{~s}$ & \\
Annealing, & $55-65$ & $15-30 \mathrm{~s}$ & \\
Extention & 72 & $1 \mathrm{~min}$ & \\
and final extension & 72 & $5 \mathrm{~min}$ & 35 \\
\hline \multicolumn{3}{l}{} \\
\hline Item & & Volume \\
\hline Nuclease-free (D.W) & & $5 \mu \mathrm{l}$ \\
Forwarding primer & & $1 \mu \mathrm{l}$ \\
Reverse primer & & $3 \mu \mathrm{l}$ \\
Nasopharyngeal swab fluid/Standard/Negative/ & $10 \mu \mathrm{l}$ \\
Positive Control & & $20 \mu \mathrm{l}$ \\
2x Master mix AddScript RT-PCR & & \\
Total volume & & \\
\end{tabular}

UHD Journal of Science and Technology | Jan 2022 | Vol 6 | Issue 1 


\subsection{Primers and Probes}

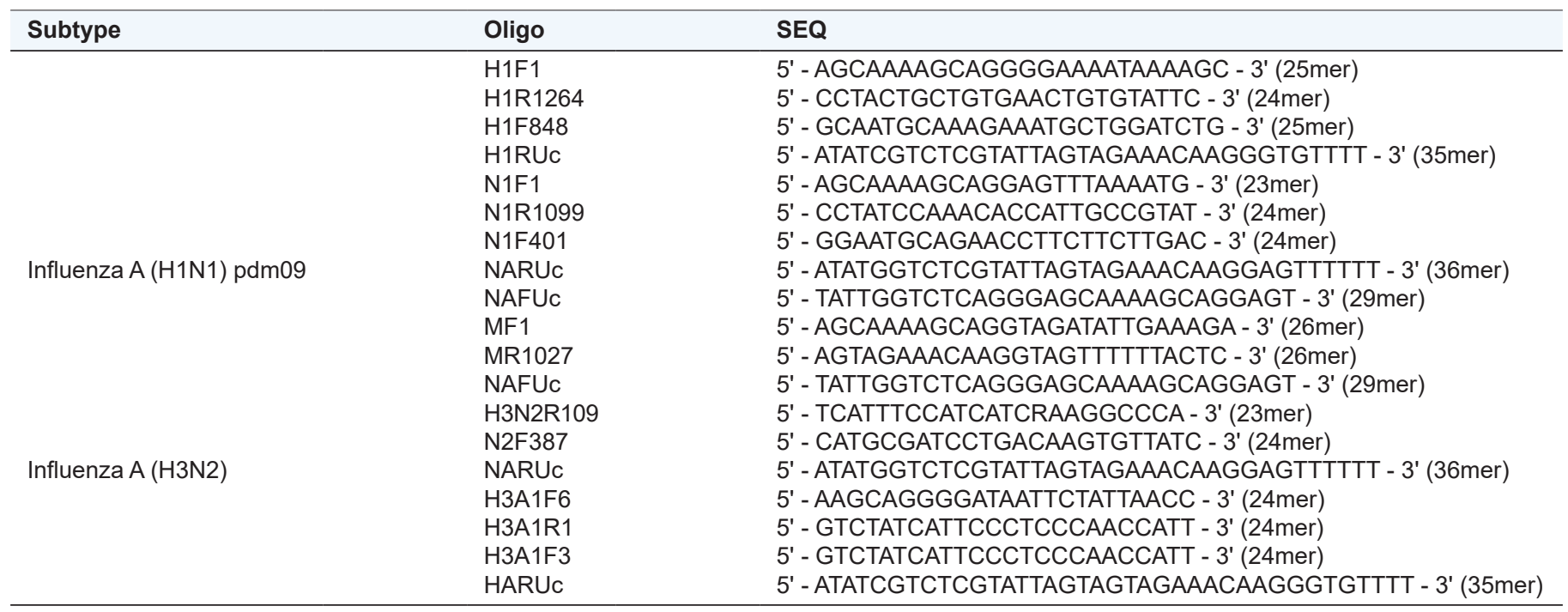

\section{RESULTS}

Both sexes were included in the current study, out of 300 participants (163 males and 137 females), (71, 23.7\%) showed seropositive results for anti-H1N1 IgG, respectively, considering the gender (Table 1). Seropositive observations considering anti-H1N1 IgM showed lower positive results comparing to anti-H1N1 IgG. It was noticed that (40, $13.33 \%$ ) cases were seropositive for anti-H1N1 IgM among males and females (Table 1). It was noticed that some tested cases were seropositive for both anti-H1N1 IgG and IgM at the same time (10\%) (Fig. 1).

The percentage of seropositive results among males was relatively higher $(56.3 \%)$ than among females $(43.7 \%)$, although there were significant differences considering the gender regarding anti-H1N1 IgG $(P<0.05)$ (Fig. 2). As in the case of IgM results, the seropositive results were higher among males (55\%) when compared with females (45\%). Statistical analysis showed significant differences between males and females considering anti-H1N1 $\operatorname{IgM}(P<0.05)$ (Fig. 2). From this ratio, 55\% were among males and 45\% among females. Furthermore, the percentage of $\operatorname{IgG}$ and IgM among males $(11.7 \%)$ was higher to compere females (7.8\%) (Fig. 2).

The PCR positive result was among seropositive males $(0.67 \%)$ only, while the seropositive females showed negative PCR results (Fig. 3).
When the relationships of certain risk factors were evaluated on the seropositive observations, it appeared that gender has significant effects on the H1N1 seropositive results considering H1N1 anti-IgG, anti-IgM $(P<0.05)$ (Table 1$)$. Moreover, As mentioned in the methodology, some of the cases were symptomatic others were asymptomatic, so depending on the presence of flu syndrome, it appeared that the occurrence of flu symptoms have significant relations with the obtained seropositive results $(P<0.05)$ which indicates that the symptoms are dependable in H1N1 diagnosis (Table 1). Studying the effects of residency indicated that it has no significant effects on the percentage of seropositive results $(P>0.05)$ (Table 1). In Addition to these factors, the effects of smoking also were evaluated, it was noticed that smoking has significant effects on the results $(P<0.05)$, so smoking can be considered as a risk factor for H1N1 infections (Table 1). Similarly, both previous history of chronic diseases and employment can be strongly related with observations recorded in the current study $(P<0.05)$ for both factors (Table 1$)$.

Depending on the complete blood count $(\mathrm{CBC})$ picture done for all studied cases, it was concluded that no valuable changes were seen between seropositive cases and negative ones $(P>$ 0.05). As well as comparison of the calculated hematologic parameters with the normal rages from reference textbooks clarified that no significant abnormal (elevation and decline) of these parameters were recorded although slight changes or elevations in some parameters were seen, but were nonsignificant $(P>0.05)$ (Table 2$)$. 
Kaziwa Ahmad Kaka Alla and Salih Ahmed Hama: Seroprevalence and molecular detection of Influenza A virus

TABLE 1: Evaluation of relations between some risk factors and H1N1 seropositive results

\begin{tabular}{|c|c|c|c|c|c|}
\hline Variables & & Anti-IgG positive (No, \%) & Anti-lgM positive (No, \%) & Anti-IgG, IgM positive (No, \%) & $P$-value \\
\hline \multirow[t]{2}{*}{ Gender } & Males & $40(13.33)$ & $22(07.33)$ & $18(06.00)$ & $P<0.05$ \\
\hline & Females & $31(10.33)$ & $18(06.00)$ & $12(04.00)$ & \\
\hline Flu symptoms & Yes & $37(12.33)$ & $23(07.67)$ & $20(06.67)$ & $P>0.05$ \\
\hline \multirow[t]{2}{*}{ Residency } & Urban & $33(11.00)$ & $19(06.33)$ & $12(04.00)$ & $P<0.05$ \\
\hline & Rural & $38(12.67)$ & $21(07.00)$ & $18(06.00)$ & \\
\hline Smoking & Smoker & $33(11.00)$ & $29(09.67)$ & $21(07.00)$ & $P<0.05$ \\
\hline Chronic diseases & No & $31(10.33)$ & $18(06.00)$ & $12(04.00)$ & \\
\hline \multirow[t]{2}{*}{ Employed } & Yes & $47(15.67)$ & $31(10.33)$ & $22(07.33)$ & \\
\hline & No & $24(08.00)$ & $09(03.00)$ & $08(02.67)$ & \\
\hline
\end{tabular}

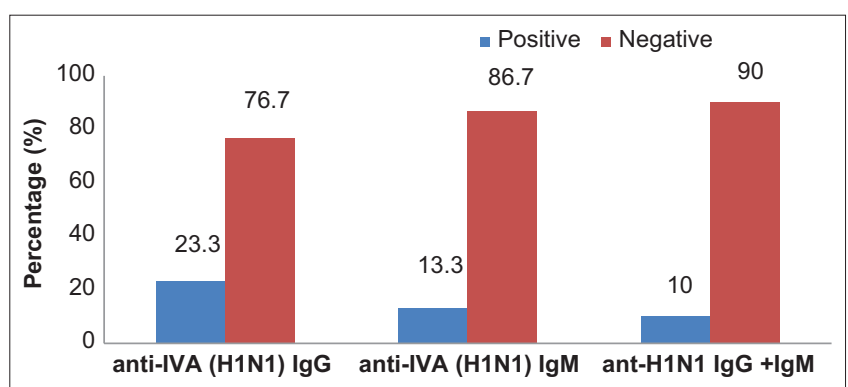

Fig. 1. Seropositive results of IVA (H1N1) among tested patients.

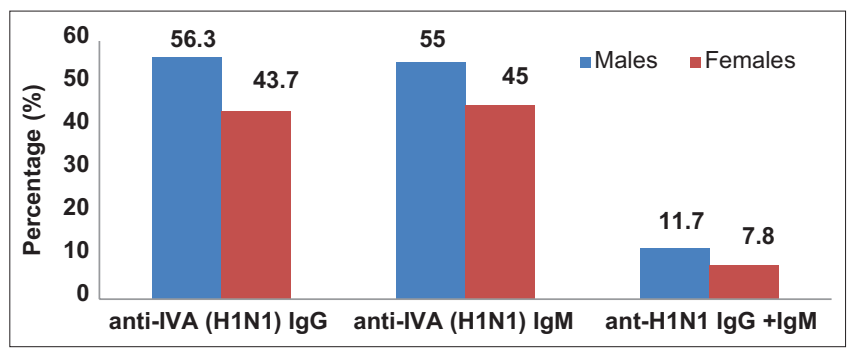

Fig. 2. Seropositive results of ant-H1N1 IgG and IgM among males and females.

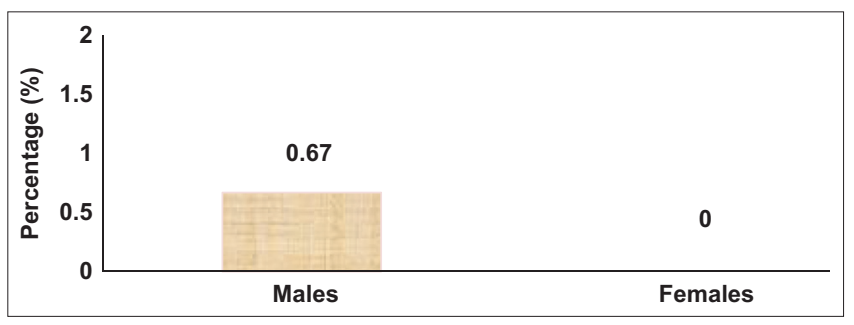

Fig. 3. Positive PCR results among males and females.

\section{DISCUSSIONS}

Life-threatening infection by influenza A virus stays behind health complaints and death worldwide. It was estimated around the world that seasonal influenza can cause about
3-5 million cases of severe illness, and about 290,000-650,000 respiratory deaths worldwide each year [11]. Certain factors may explain the low percentage rates of RT-PCR results from the current study; among them, the limited numbers of the samples, technical errors as well as high sensitivity of the viral RNA for degradation by enzymes and environmental factors, since most of the analyzed samples were previously collected and preserved in the specified hospitals. The relatively high seropositivity rates (23.3\%) of INF-A (H1N1) virus infection among the studied cases in the current study can be explained, especially since the vast majority of patients were with a previous history of flu infection. They were suspected of having an influenza virus infection. On the other hand, most of the studied cases were from Cancer treatment centers and suffering from immunologic complaints, and were at high risk for different infections including influenza. Several studies and investigators reported a higher prevalence of influenza $A$ virus infections than our observation. In a previous study, it was reported that the prevalence of influenza A virus seropositivity (anti-IgG and anti-IgM) was relatively higher than the current results [12]-[14]. Whereas the current results were in agreement with conclusions reported by other investigators [15]. It was reported that some factors were significantly effective on the seropositivity of influenza A (H1N1), which was parallel with observations recorded by a study done in the American Society of Clinical Oncology, who found that occupation, immunocompetency, previous history of chronic diseases, smoking, showed significant effects on respiratory viral infections especially influenza A virus [16]. The current observations were relatively similar and agreed with results reported by the Iranian research groups who reported in 2019 [17]. Moreover, our conclusions nearby with results reported in a study done in Switzerland [18]. Moreover, other investigators reported a relatively higher prevalence of influenza A viral infections and transmissions [19]. 
TABLE 2: Hematologic parameter evaluation of seropositive cases with normal ranges

\begin{tabular}{lcccc}
\hline $\begin{array}{l}\text { Hematologic } \\
\text { parameters }\end{array}$ & Units & $\begin{array}{c}\text { H1N1 } \\
\text { seropositive } \\
\text { (Mean } \pm \text { SD) }\end{array}$ & $\begin{array}{c}\text { Normal } \\
\text { range }\end{array}$ & $P$-value \\
\hline WBC total & $10^{9}$ & $7.4 \pm 2.2$ & $4-11$ & $P>0.05$ \\
Hemoglobin & g/dl & $11.92 \pm 1.71$ & $11.5-15.5$ & \\
RBC & $10^{12}$ & $2.72 \pm 0.88$ & $3.8-4.8$ & \\
Platelets & $10^{9}$ & $186.61 \pm 59.24$ & $150-450$ & \\
Lymphocytes & $\%$ & $28.8 \pm 7.67$ & $2-45$ & \\
Granulocytes & $\%$ & $56.48 \pm 12.73$ & $40-80$ & \\
MID & $\%$ & $7.64 \pm 1.92$ & $2-10$ & \\
\hline
\end{tabular}

Some factors may be behind the high prevalence rates of H1N1 anti-IgG and anti-IgM seropositivity among males in the current study including the cultural behavior where males mostly enter into the crowded areas without following standard protection protocols, as well as smoking are more common among males in comparison to females. These observations were in agreement with results reported by epidemiological studies conducted in different areas among different groups and populations [20]. Preparation planning surveyed by the response to the first influenza pandemic of the $21^{\text {st }}$ Century delivered a unique opportunity for construction and applying a global system of surveillance to chance both global and national needs [21]-[23]. The current work found a limited number of pandemic influenza $A$ (H1N1) among the tested cases although the vast majority of them were within the flu-like syndrome. This may be due to the other pandemic viral infection by SARS-CoV 2 which is known as COVID-19. There are mixes between symptoms for both cases that may confuse the physicians and researchers in their discissions and more other laboratory investigations are necessary to be followed. Reports achieved by other workers support this conclusion and explanation [24]. This opinion opens a gate for a fact which is essential to recognize the co-infections by way of some individual can be treated with antibiotics and antivirals [25]. The current study revealed that CBC may not help identify influenza A virus (H1N1), which was parallel to other conclusions reported by others [26], although other investigators reported that the possibility of high monocytosis and lymphopenia could be considered as a good indicator [27].

\section{CONCLUSIONS}

It was concluded that the percentage rates of anti-IgG and anti-IgM seropositivity for influenza A (H1N1) viral infections was relatively in an accepted range in Sulaymani Governorate. Smoking, previous history of chronic diseases, and the employment status of the tested cases showed to be among the significant risk factors for influenza A viral infections, especially H1N1. It was concluded that hematologic tests and parameters are not dependable in H1N1 diagnosis. Limited numbers of the studied cases showed positive results for RT-PCR comparing to the serologic investigations.

\section{REFERENCES}

[1] N. Takeshi. "Native morphology of influenza virions". Frontiers in Microbiology, vol. 2, p. 269, 2012.

[2] S. V. Bourmakina and A. García-Sastre. "Reverse genetics studies on the filamentous morphology of influenza a virus". Journal of General Virology, vol. 84, no. 3, pp. 517-527, 2003.

[3] B. Szewczyk, K. Bieńkowska-Szewczyk and E. Król. "Introduction to molecular biology of influenza a viruses". Acta Biochimica Polonica, vol. 61, no. 3, pp. 397-401, 2014.

[4] D. B. Smith, E. R. Gaunt, P. Digard, K. Templeton and P. Simmonds. Detection of influenza $C$ virus but not influenza $D$ virus in Scottish respiratory samples". Journal of Clinical Virology, vol. 74, pp. 5053, 2016.

[5] C. Brockwell-Staats, R. G. Webster and R. J. Webby. "Diversity of influenza viruses in swine and the emergence of a novel human pandemic influenza A (H1N1)". Influenza and Other Respiratory Viruses, vol. 3, no. 5, pp. 207-213, 2009.

[6] K. Wu, J. Liu, R. Saha, D. Su, V. D. Krishna, M. C. J. Cheeran and J. P. Wang. "Magnetic particle spectroscopy for detection of influenza a virus subtype H1N1". ACS Applied Materials and Interfaces, vol. 12, no. 12, pp. 13686-13697, 2020.

[7] Z. Yu, K. Cheng, H. He and J. Wu. "A novel reassortant influenza A (H1N1) virus infection in swine in Shandong Province, Eastern China". Transboundary and Emerging Diseases, vol. 67, no. 1, pp. 450-454, 2020.

[8] J. A. Pulit-Penaloza, C. Pappas, J. A. Belser, X. Sun, N. Brock, H. Zeng, T. M. Tumpey and T. R. Maines. "Comparative in vitro and in vivo analysis of $\mathrm{H} 1 \mathrm{~N} 1$ and $\mathrm{H} 1 \mathrm{~N} 2$ variant influenza viruses isolated from humans between 2011 and 2016". Journal of Virology, vol. 92, no. 22, p. e01444-18, 2018

[9] P. J. Campbell, S. Danzy, C. S. Kyriakis, M. J. Deymier, A. C. Lowen and J. Steel. "The M segment of the 2009 pandemic influenza virus confers increased neuraminidase activity, filamentous morphology, and efficient contact transmissibility to A/Puerto Rico/8/1934-based reassortant viruses". Journal of Virology, vol. 88 , no. 7 , p. 3802 , 2014.

[10] C. W. Potter. "A history of influenza". Journal of Applied Microbiology, vol. 91, no. 4, pp. 572-579, 2001.

[11] S. Davis. "The different types of flu explained-seasonal influenza, swine flu, and avian flu. SA Pharmacists Assistant, vol. 19, no. 2, pp. 10-11, 2019

[12] P. J. Gavin and R. B. Jr. Thomson. "Review of rapid diagnostic tests for influenza". Clinical and Applied Immunology Reviews, vol. 4, no. 3, pp. 151-172, 2004.

[13] M. Petric, L. Comanor and C. A. Petti. "Role of the laboratory in the diagnosis of influenza during seasonal epidemics and potential pandemics". The Journal of Infectious Diseases, vol. 194, no. Suppl 2, pp. S98-S110, 2006.

[14] S. Dellière, M. Salmona, M. Minier, A. Gabassi, A. Alanio, J. Le Goff, C. Delaugerre, M. L. Chaix and Saint-Louis CORE 
(COvid REsearch) Group. "Evaluation of the COVID-19 IgG/ IgM rapid test from orient gene biotech". Journal of Clinical Microbiology, vol. 58, no. 8, p. e01233-20, 2020.

[15] M. Von Lilienfeld-Toal, A. Berger, M. Christopeit, M. Hentrich, C. P. Heussel, J. Kalkreuth, M. Klein, M. Kochanek, O. Penack, E. Hauf, C. Rieger, G. Silling, M. Vehreschild, T. Weber, H. H. Wolf, N. Lehners, E. Schalk and K. Mayer. "Community-acquired respiratory virus infections in cancer patients guideline on diagnosis and management by the infectious diseases working party of the German society for haematology and medical oncology". European Journal of Cancer, vol. 67, pp. 200-212, 2016.

[16] R. El Ramahi and A. Freifeld. "Epidemiology, diagnosis, treatment, and prevention of influenza infection in oncology patients". Journal of Oncology Practice, vol. 15, no. 4, pp. 177-184, 2019.

[17] V. Rahmanian, M. Shakeri, H. Shakeri, A. S. Jahromi, A. Bahonar and A. Madani. "Epidemiology of influenza in patients with acute lower respiratory tract infection in South of Iran (2015-2016)". Acta Facultatis Medicae Naissensis, vol. 36, no. 1, pp. 27-37, 2019.

[18] L. P. Hariri, C. M. North, A. R. Shih, R. A. Israel, J. H. Maley, J. A. Villalba, V. Vinarsky, J. Rubin, D. A. Okin, A. Sclafani, J. W. Alladina, J. W. Griffith, M. A. Gillette, Y. Raz, C. J. Richards, A. K. Wong, A. Ly, Y. P. Hung, R. R. Chivukula, C. R. Petri, T. F. Calhoun, L. N. Brenner, K. A. Hibbert, B. D. Medoff, C. C. Hardin, J. R. Stone and M. Mino-Kenudson. "Lung histopathology in coronavirus disease 2019 as compared with severe acute respiratory syndrome and H1N1 influenza". Chest, vol. 159, no. 1, pp. 73-84, 2020.

[19] E. Kenah, D. L. Chao, L. Matrajt, M. E. Halloran and I. M. Jr. Longini. "The global transmission and control of influenza". PLoS One, vol. 6, no. 5, p. e19515, 2011.

[20] V. M. Konala, S. Adapa, V. Gayam, S. Naramala, S. R. Daggubati, C. B. Kammari and A. Chenna. "Co-infection with influenza A and COVID-19". European Journal of Case Reports in Internal
Medicine, vol. 7, no. 5, p. 001656, 2020.

[21] S. Briand, A. Mounts and M. Chamberland. "Challenges of global surveillance during an influenza pandemic". Public Health, Vol. 125, no. 5, pp. 247-256, 2011.

[22] B. N. Archer, C. Cohen, D. Naidoo, J. Thomas, C. Makunga, L. Blumberg, M. Venter, G. Timothy, A. Puren, J. McAnerney, A. Cengimbo and B. Schoub. "Interim report on pandemic H1N1 influenza virus infections in South Africa, April to October 2009: Epidemiology and factors associated with fatal cases". Eurosurveillance, vol. 14, no. 42, pp. 19369, 2009.

[23] D. Miyazawa. "Why obesity, hypertension, diabetes, and ethnicities are common risk factors for COVID-19 and H1N1 influenza infections". Journal of Medical Virology, vol. 93, no. 1, pp. 127-128, 2021.

[24] Z. A. Memish, A. M. Assiri, R. Hussain, I. Alomar and G. Stephens. "Detection of respiratory viruses among pilgrims in Saudi Arabia during the time of a declared influenza A (H1N1) pandemic". Journal of Travel Medicine, vol. 19, no. 1, pp. 15-21, 2012.

[25] Z. Shimoni, J. Glick and P. Froom. "Clinical utility of the full blood count in identifying patients with pandemic influenza A (H1N1)". The Journal of Infection, vol. 66, no. 6, pp. 545-547, 2013.

[26] O. Coșkun, I. Y. Avci, K. Sener, H. Yaman, R. Ogur, H. Bodur and C. P. Eyigün. "Relative lymphopenia and monocytosis may be considered as a surrogate marker of pandemic influenza $A$ (H1N1)". Journal of Clinical Virology, vol. 47, no. 4, pp. 388-389, 2010.

[27] Y. Egawa, S. Ohfuji, W. Fukushima, Y. Yamazaki, T. Morioka, M. Emoto, K. Maeda, M. Inaba and Y. Hirota. "Immunogenicity of influenza A (H1N1) pdm09 vaccine in patients with diabetes mellitus: With special reference to age, body mass index, and HbA1c". Human Vaccines and Immunotherapeutics, vol. 10, no. 5, pp. 1187-1194, 2014. 